This is the author's version of a work that was published in the following source:

Babrowski, S.; Jochem, P.; Fichtner, W. (2014).

\title{
Electricity Storage Systems and Their Allocation in the German Power System $\square$
}

Operations Research Proceedings 2013: Selected Papers of the International Conference on Operations Research, OR2013, organized by the German Operations Research Society (GOR), the Dutch Society of Operations Research (NGB) and Erasmus University Rotterdam, September 3-6, 2013. Ed.: D. Huisman, 7 - 13, Springer International Publishing, Cham (Switzerland). doi:10.1007/978-3-319-07001-8_2 2 중

Please note: Copyright is owned by the author(s) and / or the publisher. The commercial use of this copy is not allowed. 


\title{
Electricity Storage Systems and Their Allocation in the German Power System
}

\author{
Sonja Babrowski, Patrick Jochem and Wolf Fichtner
}

\begin{abstract}
The need for daily electricity storage systems increases with the growing share of volatile renewable energy in the generation mix. Since the loca-tion of decentralized electricity generation (based on reneweable energy resource potentials) and electricity demand (depending on industrial facilities and population density) in Germany are geographically apart from each other, at the same time more electricity has to be transported. At certain times, this might challenge the transmis-sion grid. Storage systems can be used for storing the surplus production of renewable energy and also help to prevent congestions in the grid. However, besides the tech-nical feasibility there are economic criteria decisive for the installation of storage systems. These depend firstly on potential alternative technologies as gas turbines or the load shift potential of electric vehicles and secondly on the price development of storage systems. In order to estimate the future demand and the strategic allocation of daily storage systems in this context, expansion options for storage systems are implemented in the optimizing energy system model PERSEUS-NET-TS. This is a myopic material and energy flow model with an integrated nodal pricing approach. A mixed-integer optimization calculates the expansion and use of power plants in Ger-many until 2040 considering the DC restrictions of the transmission grid. Hence, the commissioning and allocation of storage systems in the German transmission grid is determined when the government target of $60 \%$ renewable feed-in by 2040 is met. For this paper about every forth car in Germany is considered to drive electrically by 2040. When they are charged uncontrolled, directly after arrival the results are that by 2040 about $19 \mathrm{GW}$ of storage systems are commissioned. Most are built closely to generation centers, but some are allocated close to bottlenecks in the transmission grid instead. When load shifting of the demand for electric mobility is allowed in terms of a controlled charging the required daily storage capacity could be reduced by more than half, so that only $8 \mathrm{GW}$ are needed in 2040 .
\end{abstract}

S. Babrowski $\cdot$ P. Jochem $\cdot$ W. Fichtner

Karlsruhe Institute of Technology (KIT), Institute for Industrial Production, Hertzstr. 16,

76187 Karlsruhe, Germany

e-mail: Sonja.Babrowski@kit.edu 


\section{Introduction}

According to the objectives of the Federal Government in Germany $60 \%$ of the gross electricity generation should be from renewable sources by 2040 [5]. Because of the volatile supply of wind and solar power, this is not going to work without adjustments of the transmission grid and either an additional thermal (reserve) power plant fleet or electricity storage systems. So far, electricity has mostly been generated at the time and place where it was needed. With the construction of large wind farms in the North and Baltic Sea this is going to change. In the future, generated electricity has to be harmonized with the demand in terms of place and time by transporting and storing it. Storage systems seem to be an alternative to the curtailment of renewables and could also serve as peak-load generation unit. Simultaneously, storage systems can be used for congestion management and thus lead to an improved utilization of the existing transmission capacities.

In the following, the commissioning and use of storage systems in the context of the future energy system in Germany is calculated with the energy system model PERSEUS-NET-TS. Possible alternative technologies such as gas turbines or load shifting through electric vehicles (EVs) are taken into account as well as restrictions due to the transmission grid.

\section{The Energy System Model PERSEUS-NET-TS}

PERSEUS-NET-TS is a bottom-up model of the German energy system. It is written in GAMS and uses the CPLEX solver. Depending on the setting it is solved by linear or mixed-integer programming. It is a myopic follow-up model of PERSEUS-NET [2] with a focus on daily storage systems. Besides the generation system a DC power flow model of the high and extra high voltage grid (220 and $380 \mathrm{kV})$ is integrated. Until 2040 PERSEUS-NET-TS calculates the commissioning and dis-patch of the generation system at least for every fifth year. The model endogenously decides on commissioning coal, lignite, combined-cycle and gas power stations, as well as storage systems. These power plant extension options are modeled at most of the 442 network nodes depicted in the model and their configuration is based on [3]. About 550 modeled transmission lines connect these nodes. Larger power plants (over $100 \mathrm{MW}$ ) of the current generation system are directly assigned to specific grid nodes. The capacities of smaller power plants are aggregated by NUT3 regions (county level). Their cumulated capacities are assigned to the two closest grid nodes, inverse to the distance from the center of the region to them. In PERSEUS-NET-TS existing power plants are decommissioned 40 years after their commission-ing. The conventional electricity demand is also calculated for each grid node based on the GDP and the number of inhabitants of adjacent NUT3 regions [2]. Besides this demand there is a demand for electric mobility integrated for each country based on forecasts made by the German Aerospace Center [6]. Accordingly $22 \%$ of the 
personal vehicles in Germany are going to be electric by 2030. This share remains stable until 2040 for the PERSEUS-NET-TS calculations. Depending on the settings this extra demand can either be charged controlled or uncontrolled directly after arriving at a charging opportunity at home or at the work place. When charged con-trolled the only restriction is that each day the needed amount has to be charged, but the model decides endogenously at which hour during the plug-in time. The driving force of the optimization is the exogenously given hourly electricity demand for a winter and a summer week. This hourly demand must be met at each grid node considering restrictions of the transmission grid and techno-economic constraints of the generation system. The electricity can be either generated at the grid node with the assigned power plants or transmitted over the grid from one of the neighboring nodes. The decision relevant expenditures are minimized for each of the considered periods. These expenditures include fuel costs and $\mathrm{CO}_{2}$ certificate prices that are based on the World Energy Outlook 2012 [7]. Furthermore, the variable costs of the generation are considered, as well as costs for load changing of the thermal power plants (coal, lignite and gas-combined cycle plants). The fixed costs of the resulting power plant fleet in the current period are also added as well as investments for new power plants.

The commissioning of storage systems is allowed from 2020 on. The capital expenditures for storage systems are assessed to 1,000 EUR/kW in 2020 and are gradually reduced to $700 \mathrm{EUR} / \mathrm{kW}$ in 2040 . Additionally, for battery storage sys-tems there is a fixed ratio of installed capacity to storage volume ( $\mathrm{kW}$ to $\mathrm{kWh}$ ) of 1 to 5 assumed. This ratio is chosen according to the characteristics of daily storage systems in [1]. With the use of PERSEUS-NET-TS it is possible to determine the technology and the allocation of new generation plants. In order to prevent storage systems from storing and generating at the same time binary variables are needed for each hour and each storage. Thus, the model has to be solved via a mixed-integer optimization. With 336 considered hours (two weeks) for each period, the calcu-lation time increases significant with every implemented storage option. Through the storing and generating at the same time, the efficiency of the storage systems can be used to "waste" electricity. This may make sense within the optimization to avoid the shutdown of thermal power plants with load changing costs or to meet the exogenously given targets for the renewable feed-in. To avoid this simultaneous bidirectional use of storage systems, we chose a two-step approach for this analyses (see Fig. 1). First, ideal storages with an efficiency of $100 \%$ are implemented. In this case PERSEUS-NET-TS can be solved linearly with a relatively short computation time of about $9.5 \mathrm{~h} .{ }^{1}$ Each of the calculated 7 periods consists of about 2.7 mil-lion equations and 2.3 million variables. In this step, about 350 nodes distributed across Germany are provided with extension options for battery storage systems. In addition, a total of 30 pump storage power plants are considered, of which 10 are integrated as expansion option because they are currently in the planning phase.

\footnotetext{
${ }^{1}$ With the use of 6 threats on Windows Server 2008 R2 Enterprise, Intel(R) Xeon(R) CPU E5-1650 @ 3.20 GHz 3.20 GHz; 96 GB RAM; 64 Bit.
} 


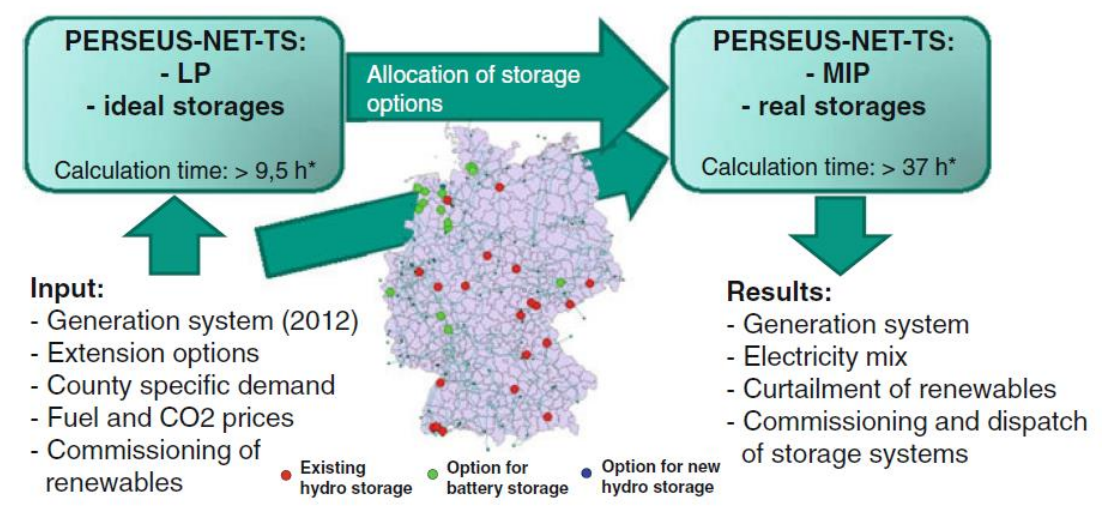

Fig. 1 Approach to reduce the needed binary variables

The resulting generation system of 2040 is analyzed in terms of the allocation of endogenously build storage systems. Only the grid nodes where ideal storage systems have been commissioned with the linear optimization are possible allocations for real storage systems in the following mixed-integer optimization. Storage systems in the mixed-integer optimization are modeled with an efficiency of about $80 \%$. The results presented below are based on this recalculation of PERSEUS-NET-TS as a mixedinteger problem with a calculation time of over $37 \mathrm{~h}$.

\section{Results}

The development of the thermal generation system is a key result of PERSEUS-NETTS. In 2040 a given demand of about $530 \mathrm{TWh}$ has to be covered, of which $42 \mathrm{TWh}$ occur due to electric mobility (about $8 \%$ ). The development of the renewables is exogenously given and has been derived from the German pilot study 2011 of the Federal Ministry of the Environment [4]. Overall, the installed capacity will increase in Germany until 2040 to about $224 \mathrm{GW}$, but at the same time the thermal power plant fleet is declining to about $47 \mathrm{GW}$ (see Fig. 2, left). The commissioning of storage systems starts 2030 when $50 \%$ renewables are targeted and peaks 2040 with an target of $60 \%$ and battery prices of $700 \mathrm{EUR} / \mathrm{kW}$, respectively $140 \mathrm{EUR} / \mathrm{kWh}$. With about 19 GW storage systems represent about $8 \%$ of the installed capacity by $2040.12 \mathrm{GW}$ consist of battery storage systems. Furthermore, considering only the endogenous installed power plants, i.e. the commissioning of new thermal power plants and storage systems, the commissioned storage systems represent about $40 \%$ of the endogenously installed capacity until 2040 (see Fig. 2, right). According to the PERSEUS-NET-TS results most of the battery storage systems are built in the north-west near to the coast and thus close to the feed-in from offshore wind farms 

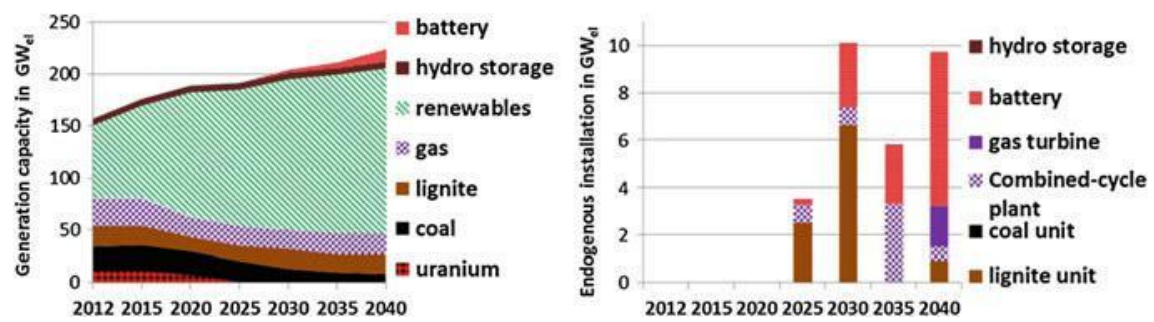

Fig. 2 Installed capacity (left) and endogenous commissioned capacity (right)
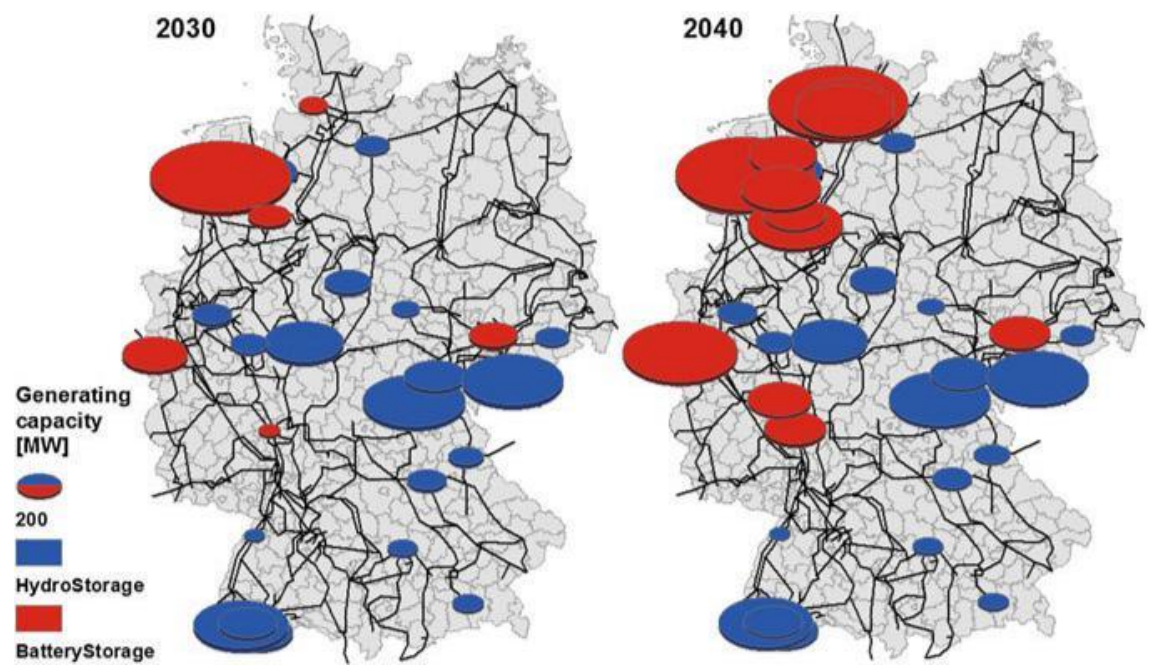

Fig. 3 Allocation of endogenously commissioned storage systems
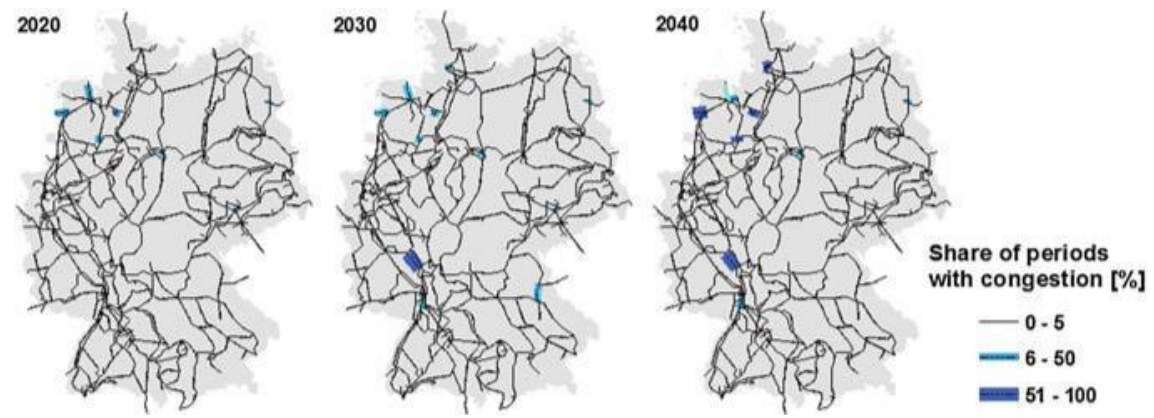

Fig. 4 Congestions in the transmission grid 
in the North Sea (see Fig. 3). However, looking at the bottleneck in the transmission grid in the west of Germany (see Fig. 4) and the storage systems allocated on both sides of that bottleneck in 2040 (see Fig. 3) it becomes clear that storage systems are also used for grid management within the optimization.

In comparison to the results of an uncontrolled charging the need for storage systems decreases by $55 \%$ to only $8 \mathrm{GW}$ when the charging process of the EVs is controlled. In that case only about $2 \mathrm{GW}$ battery storage systems are endogenously commissioned in the northwest.

\section{Conclusion and Outlook}

Through the implementation of storage options on transmission grid level in the energy system model PERSEUS-NET-TS we showed that the commissioning of stor-age systems in Germany is going to make sense considering an increasing renewable feedin. According to the results the generation system should consist of about $8 \%$ storage systems by 2040 (60 \% renewables). These storage systems should be in general allocated close to the generation centers. Furthermore, the results indicate that a strategic allocation of storage systems might also help to prevent bottlenecks in the transmission grid. A second calculation showed that a big part of the needed flexibility could also be granted through a controlled charging of EVs instead. This alternative is certainly more economic assuming that the EV penetration rate is high enough and that the technology and the acceptance for an automatic controlled charg-ing exists. However, interpreting these results it has to be kept in mind, that in favor to storage systems no net exchange with neighboring countries was allowed in the model and that on the other hand no stochastics were considered for the renewable feed-in. A more detailed analysis of the interaction between storage systems, renew-able feed-in, power plants and the transmission grid is therefore going to be subject for further scientific work with PERSEUS-NET-TS.

\section{References}

1. Association for Electrical, Electronic and Information Technologies (VDE). (2012). Energiespe-icher für die Energiewende Speicherbedarf und Auswirkungen auf das Übertragungsnetz für Szenarien bis 2050. Frankfurt.

2. Esser-Frey, A. (2012). Analysing the regional long-term development of the German power system using a nodal pricing approach. Dissertation, Karlsruher Institute of Technology (KIT), Karlsruhe.

3. German Federal Ministry for the Environment, Nature Conservation and Nuclear Safety (BMU). (2010). Long-term scenarios and strategies for the deployment of renewable energies in Germany in view of European and global developments-Pilot study. Berlin.

4. German Federal Ministry for the Environment, Nature Conservation and Nuclear Safety (BMU). (2011). Long-term scenarios and strategies for the deployment of renewable energies in Germany in view of European andglobal developments-Pilot study. Berlin. 
5. German Federal Ministry of Economics and Technology (BMWi) and German Federal Ministry for the Environment, Nature Conservation and Nuclear Safety (BMU). (2011). The Federal Government's energy concept of 2010 and the transformation of the energy system of 2011. Berlin.

6. Heinrichs, H. (2013). Analyse der langfristigen Auswirkungen von Elektromobilität auf das deutsche Energiesystem im europäischen Energieverbund unter Berücksichtigung von Netzrestriktionen. Dissertation, Karlsruher Institute of Technology (KIT), Karlsruhe.

7. International Energy Agency, (IEA). (2012). World energy, outlook. 